\title{
Protein encoded by the exuperantia gene is concentrated at sites of bicoid mRNA accumulation in Drosophila nurse cells but not in oocytes or embryos
}

\author{
Paul M. Macdonald, Sandy Ka-Shing Luk, and Madison Kilpatrick \\ Department of Biological Sciences, Stanford University, Stanford, California 94305 USA
}

\begin{abstract}
Formation of the anteroposterior gradient of the bicoid (bcd) protein morphogen in Drosophila occurs as a consequence of the prelocalization of $b c d$ mRNA to the anterior pole of the oocyte. bcd mRNA localization requires at least three genes, with the exuperantia (exu) gene acting earliest in the pathway. We have cloned and characterized the exu gene. Notably, we find that exu protein is colocalized with bcd mRNA during the early phase of localization, when bcd mRNA is positioned at the apical regions of the nurse cells. However, there is no colocalization at the later stage when bcd mRNA is transferred from the nurse cells to the anterior pole of the oocyte. There is no detectable exu protein in embryos. Therefore, exu acts only in initiating bcd mRNA localization and does not play a persistent role in that process.
\end{abstract}

[Key Words: mRNA localization; Drosophila; exuperantia gene; oogenesis; bicoid]

Received August 12, 1991; revised version accepted October 16, 1991

In Drosophila, elaboration of the body plan in the head and thoracic regions is directed in large part by an anterior patterning system (Nüsslein-Volhard et al. 1987). Genetically identified components of this system include bicoid $(b c d)$ (Frohnhöfer and Nüsslein-Volhard 1986), which encodes a localized patterning activity, and several other genes required to localize bcd activity (Schüpbach and Wieschaus 1986; Frohnhöfer and Nüsslein-Volhard 1987; Stephenson et al. 1988; St. Johnston et al. 1989). Bcd protein is distributed in a concentration gradient along the anteroposterior axis of the embryo, peaking at the anterior pole (Driever and Nüsslein-Volhard 1988a). This gradient provides positional information in a concentration-dependent fashion (Driever and Nüsslein-Volhard 1988b, 1989; St. Johnston et al. 1989). Formation of the gradient is made possible by the prelocalization of $b c d$ transcripts to the anterior pole of the oocyte during oogenesis (Frigerio et al. 1986; Berleth et al. 1988). All other known components of the anterior system, the exuperantia $|e x u|$, swallow $|s w w|$, and staufen (stau) genes, are required for bcd mRNA localization (Frohnhöfer and Nüsslein-Volhard 1987; Stephenson et al. 1988; St. Johnston et al. 19891.

One mechanism for localizing $b c d$ mRNA to the anterior end of the oocyte was suggested by the spatial organization of the egg chamber. Each egg chamber contains a cluster of nurse cells connected by cytoplasmic bridges to the anterior pole of a single oocyte (King 1970). After synthesis in the nurse cells, $b c d$ mRNA is trans- ferred to the oocyte; trapping by a receptor at the site of entry could allow for anterior localization (Frohnhöfer and Nüsslein-Volhard 1987). This simple model may be partially correct, but a careful analysis of bcd mRNA localization throughout oogenesis clearly demonstrated that it is incomplete (St. Johnston et al. 1989). bcd mRNA not only is localized within the oocyte but also to the apical regions of individual nurse cells. Therefore, the localization process begins before $b c d$ mRNA enters the oocyte. Furthermore, St. Johnston et al. (1989) were able to describe four stages in the localization pathway and to identify the stages disrupted by mutations in the various anterior patterning genes. In exu mutants, bcd mRNA localization is abolished by the second stage and is somewhat aberrant even in the first stage. Mutations in the sww gene alter localization at a later stage, when the $b c d$ transcripts are being positioned at the anterior margin of the oocyte. Finally, repositioning of $b c d$ mRNA within the oocyte is defective in stau mutants. Among the identified genes, then, exu seems to act first in the localization pathway. Berleth et al. (1988) proposed previously that the exu product binds directly to $b c d$ mRNA.

Here, we report the cloning and molecular characterization of the exu gene and describe the expression and localization of exu transcripts and protein during oogenesis. Our results do not support the notion that exu protein binds directly and persistently to bcd mRNA. Instead, they suggest a somewhat different role, in which 
exu binds $b c d$ mRNA transiently and perhaps indirectly, associating it in the nurse cells with components of the localization machinery.

\section{Results}

Molecular characterization of the exu gene

Genomic DNA from the exu region was cloned using a p-element-induced allele provided by T. Schüpbach (see Materials and methods). A transcription unit expressed in ovaries, as expected for $e x u$, was identified by probing Northern blots of ovarian RNA with various restriction fragments from the exu region. Two lines of evidence prove that this gene is exu. First, P-element transformation with a DNA fragment containing the transcription unit rescues the maternal-effect lethality of an exu mutant (Fig. 1; Materials and methods). Second, sequence analysis of genomic DNA from the $e x u^{S C}$ mutant reveals the existence of a novel termination codon within the coding region of the gene (Fig. 2). In addition, this region has a restriction map essentially the same as that described by Hazelrigg et al. (1990) for the exu region.
Expression of exu occurs in a sex-specific fashion; one transcript of $\sim 2.3 \mathrm{~kb}$ is present only in adult females and early embryos, and a male-specific transcript of $\sim 3.0 \mathrm{~kb}$ first appears in late larval stages and persists into adulthood (Fig. 1). This male-specific expression was first noted by Hazelrigg et al. (1990), who demonstrated further that exu mutants are defective in spermatogenesis. As our analysis was undertaken to explore the role of exu in oogenesis, the male expression pattern is not addressed further. Nevertheless, we did wish to learn if the male and female transcripts encoded the same protein. If so, exu might be expected to perform the same function in the two distinct developmental processes. Toward this end, both male and female transcripts were defined further by isolation and characterization of ovarian and male cDNA clones. The DNA sequence was determined for each of the longest ovarian and male cDNAs, as well as for the corresponding genomic region (Fig. 2). Although none of the cDNAs are full length, the longest ovarian CDNA contains all of a single long open reading frame (ORF). The male cDNA is incomplete at the $5^{\prime}$ end and therefore lacks part of the ORF. Nevertheless, the
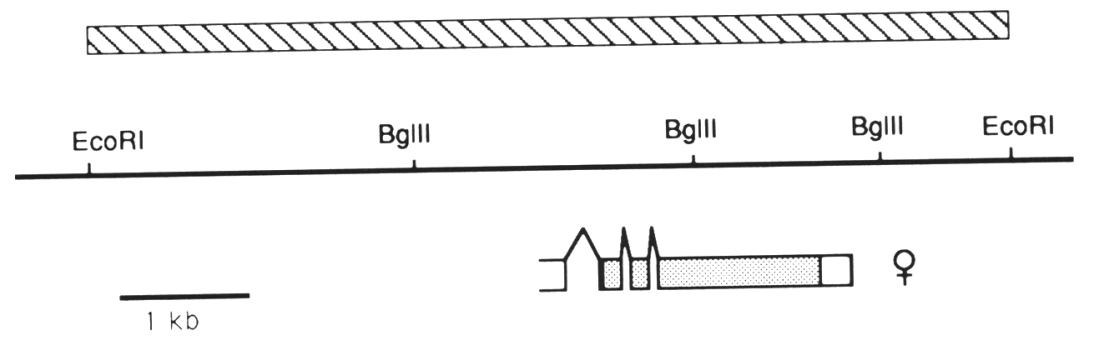

Figure 1. Structure and temporal expression pattern of the exu gene. (Top) Map of the exu genomic region and organization of male and female exu mRNAs. The restriction map of genomic DNA shows all BglII and EcoRI sites. Indicated above the map is the EcoRI restriction fragment used to construct a rescuing P-element transposon. The longest female and male cDNAs are shown below the map, with the stippled region representing the long ORF. The 5 ' ends of the transcripts have not been mapped. (Bottom) Northern blot analysis of exu transcripts during development. A blot of staged samples of poly(A) ${ }^{+}$RNA (provided by $\mathrm{M}$. Kuroda and Y. Kim) was probed with a labeled restriction fragment from an exu cDNA. RNA samples were as follows: $(0-3,6-12,12-18 \mathrm{hr})$ from embryos of the given ages after egg laying; (L1, L2, L3) from first-, second-, and third-instar larvae, male or female as indicated; $(\mathrm{P} 1, \mathrm{P} 2, \mathrm{P} 3)$ from early, mid-, or late pupae, male or female as indicated; (adult males or females) as indicated. A male transcript of $\sim 3.0 \mathrm{~kb}$ is first detected in third-instar larvae and is present throughout all later stages. A female transcript of $\sim 2.3 \mathrm{~kb}$ is present in adult females. In addition, this transcript is present in early embryos, presumably through maternal contribution.

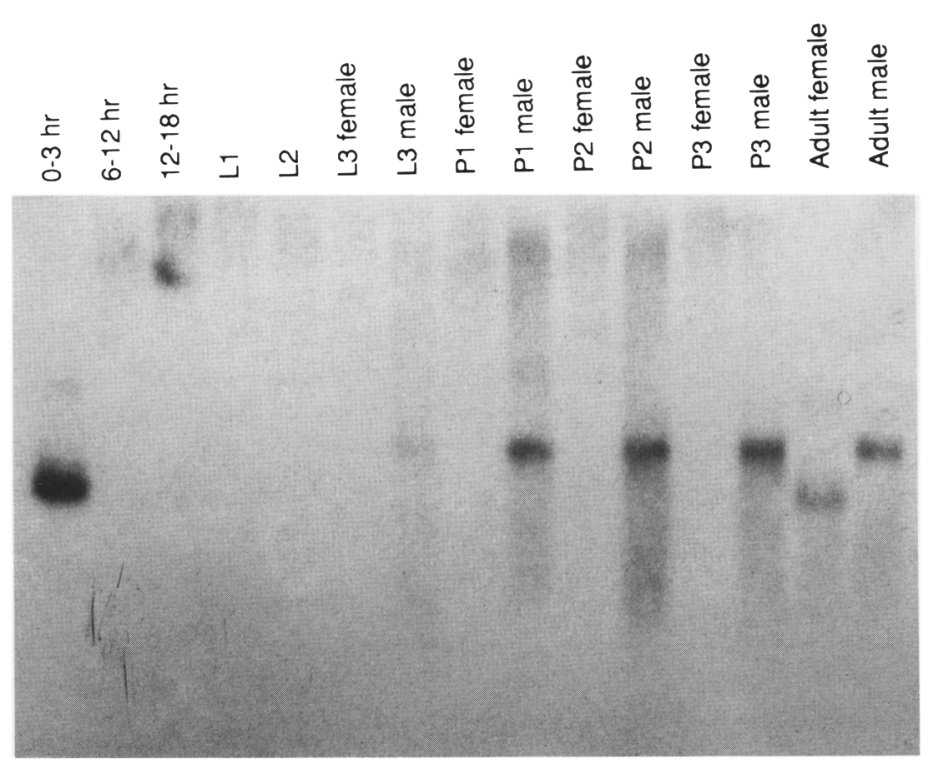


male cDNA does have a difference relative to the ovarian cDNA that can fully account for the difference in transcript size. In male transcripts one polyadenylation signal is spliced out and a downstream site is used, whereas the upstream polyadenylation site is retained and used in female transcripts. This splicing difference increases the predicted length of the transcript by $\sim 630$ nucleotides but does not alter the protein-coding region. Because male and female proteins migrate similarly in SDS-polyacrylamide gel electrophoresis (SDS-PAGE) (Fig. 3), it is likely that male and female proteins are identical.

Translation of the exu ORF predicts a $58-\mathrm{kD}$ protein, assuming that the first ATG in the ORF is used for initiation. This is the case apparently, as a bacterially produced protein initiated at that ATG comigrates in SDSPAGE with a form of the exu protein present in both ovaries and testes, as determined by Western blot analysis with polyclonal antisera directed against the exu protein (Fig. 3). Under favorable conditions, the ovarian exu protein is resolved into a series of distinct bands, with the fastest-migrating form comigrating with bacterially produced exu protein. Because there are no alternate upstream ATG codons in the same reading frame, the additional bands probably represent post-translationally modified forms of the protein.

The amino acid sequence of exu protein provides no clear indication of its function. Overall, exu protein has an amino acid composition typical of Drosophila proteins, except for an unusually high proportion of serine residues, $12.4 \%$ as compared with $7.6 \%$ (M. Ashburner, as cited in Smoller et al. 1990). Some of these serine residues are present in a Ser- $x$ repeat unit (amino acids 206-235). Several RNA-binding proteins include clusters of Ser-Arg or Arg-Ser repeats (e.g., Mancebo et al. 1990). In the exu Ser- $x$ repeat, $x$ is never arginine and is most frequently glycine. Only two Ser-Arg dipeptides are found in the entire exu protein. As in many Drosophila genes (Wharton et al. 1985), exu has an opa-like repeat encoding a run of asparagine residues. Other regions are enriched for a single amino acid, most notably arginine between residues 419 and 427 . One segment of 42 amino acids (340-381) conforms to the heptad repeat unit of coiled-coil proteins (Cohen and Parry 1986). exu does not appear to encode a membrane protein, having no likely signal sequence or membrane-spanning domain. Finally, comparison of the exu protein sequence with those in the GenBank and EMBL data bases reveals no striking similarities.

\section{Post-transcriptional control of exu expression}

During oogenesis, exu is required to localize $b c d$ mRNA. To understand the role of exu, it would be useful to know whether exu gene product, either mRNA or protein, is also localized. We have therefore monitored the expression and distribution of exu products, first by Northern and Western blot analyses (Figs. 1 and 3). Unexpectedly, although exu mRNA is present in both ovaries and embryos (Fig. 1), exu protein can be detected only in ovaries (Fig. 3). Identical results were obtained with antisera raised against an almost full-length exu protein, an amino-terminal part of exu protein, or a carboxy-terminal part of exu protein (see Materials and methods). This result contrasts sharply with what has been found for certain other proteins involved in localization of spatial cues, such as BicaudalD and vasa, which are present in both ovaries and embryos (Hay et al. 1988, 1990; Wharton and Struhl 1989; Lasko and Ashburner 1990). Therefore, it seems that exu function is limited to the ovary. Because bcd mRNA is strictly localized in both ovaries and embryos, the role of the protein encoded by exu must not entail persistent binding to bcd mRNA. Rather, the role of exu must necessarily be a transient one.

\section{Concentration of exu protein at sites of bcd $m R N A$ deposition}

We also examined the spatial distribution of exu mRNA and protein in ovaries, in large part to determine whether there was any correspondence between sites of $b c d$ mRNA localization and exu product distribution. Before describing the results, we review briefly the patterns of $b c d$ mRNA localization during oogenesis (Frigerio et al. 1986; Berleth et al. 1988; Stephenson et al. 1988; St. Johnston et al. 1989). In stage $5-6, b c d$ mRNA is detected first in the egg chamber, being restricted to the oocyte [stages are as described by King (1970) and Mahowald and Kambysellis (1978)]. By stage 8, bcd mRNA in the oocyte is restricted noticeably to the anterior margin, a situation that persists for the remainder of oogenesis. Starting in stage $9, b c d$ transcripts also appear in the nurse cells; within each nurse cell bcd mRNA is concentrated apically, between the outer membrane and the nucleus. At the same stage, $b c d$ mRNA in the oocyte is restricted to the anterior margin. This pattern persists until stage 10B-11, when the nurse cell $b c d$ mRNA is transferred to the oocyte and localized specifically at the anterior pole.

Examination of exu mRNA expression in ovaries revealed no comparable spatial pattern (Fig. 4). Low levels of exu mRNA are present in the germarium and throughout the cytoplasm of early-stage egg chambers. In stage 3 and 4 egg chambers, exu mRNA is concentrated in the oocyte, as is $b c d$ mRNA at later stages. From stage 8-10, high levels of exu mRNA are present in the nurse cells. In some preparations there is a nonrandom distribution of the transcripts, with higher levels present in the posterior nurse cells relative to the more anterior nurse cells. Nevertheless, exu mRNA distribution clearly does not parallel that of $b c d$ mRNA.

A very different result was obtained when ovaries were examined for the distribution of exu protein (Fig. 5). The protein appears initially in regions 2 and 3 of the germarium, where it is spread throughout the cytoplasm of all cells. In stage 1 egg chambers, exu protein becomes concentrated in the oocyte. This pattern persists to stage 6 . By stage 7 , the oocyte staining begins to be overshadowed by the accumulation of exu protein in the nurse cells. Within the individual nurse cells, exu protein be- 
Downloaded from genesdev.cshlp.org on April 26, 2023 - Published by Cold Spring Harbor Laboratory Press

\section{Macdonald et al.}

comes noticeably concentrated at the regions where $b c d$ mRNA is concentrated. Distributions of exu protein and $b c d$ mRNA are compared in Figure 6; the similarity ob- served in these and other egg chambers is striking. During stage 10, accumulation of exu protein in the nurse cells continues until there is a high level of protein

GATATCGATACCCTGTCATCTCTGGCGCAACCATT TGAAATTCGTCATCCCTGATCCTCTTATCAGTTCTTGTCTGCGCTTTTGTCCAAATATTTGTTGTTTACCCACCAATTT TGCCGG CTAATAATTGGAAAAAAATTTATTTACAAGCTGAAAGACTATATTTTATTATAGCAGCGGTAAAAATATTCTGCAAAAAGTTT TCACCTGCACAGTGGGCGTTGTGGCAAGATGTGGACG AGT TGCAGCTGTCTAACCCATCGTACTTAAGTCAAAAACCTCGATTAGCAGGCTT TGCATATG TCAAATTCGCGCACTTTTCCTAGGCCGTCGGGTGCATCAGGAAATTATTCATTACGT

TTTAGTTAGTCGTACGAATTGTTTCTTATTTGTGAAAGCTCGTCGAACAGAAGCAAATTTCGCTTTAACCTTTTGAAAAATAAAGGAAAAAGTTCGTAAAAAGCGAAAGAGCCCATCGAA

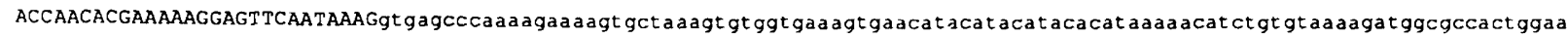
gaaaccgttagttgtagcttgggtttaatagactcttgaaattcgtagccegtcacttcatatcgaaatctagtgaaagcggttcgcgtt ttgcaaaggaaatcggttccttaaa

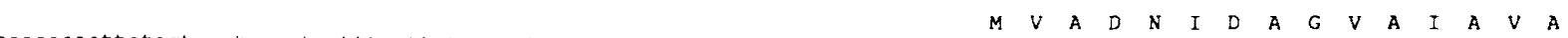
aaaaaattctagt gactcagctaat tcgttatccgaat $t$ tctagATTGCTT TTCGCAGATCATATAAGAAAATGGTTGCCGATAACATCGATGCCGGAGTGGCCAT'TGCCGICGCC

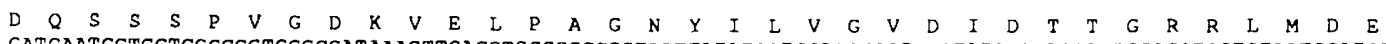
GATCAATCCTCGTCGCCCGTGGGCGATAAAGTTGAGCTGCCGGCCGGTAATTATATCCTGGTGGGCGTGGATATCGACACCACTGGACGTCGTCTAATGGATGAGgtaat aCCCCCT GaC $\begin{array}{llllllllllllllllllllll}I & V & Q & L & A & A & Y & T & P & T & D & H & E & E & Q & Y & I & M & P & Y & M & N\end{array}$ tgccgtt agatcgttcgtcgttcggt cctaaccccact gegataa acccacagATTGTCCAGCTGGCCGCTTATACACCCACCGACCACTTCGAGCAGTACATCATGCCATATATGAAT $\begin{array}{llllllllllllllllllllllllllllllllllll}L & N & P & A & A & R & Q & R & H & Q & V & R & V & I & S & I & G & E & Y & R & M & L & K & S & M & Q & T & Y & K\end{array}$ CTGAATCCAGCTGCTCGCCAGCGTCATCAAGTTCGTGTTATTTCGATTGGCTTTTATCGTATGCTGAAGTCGATGCAGACTTATAAGgtgagt CCagt gCagt CCagt CCat t aatagt $\begin{array}{llllllllllllllllllllllll}I & I & K & S & K & S & E & I & A & A & L & K & D & F & L & N & W & L & E & O & L & K & T & K\end{array}$ ggcagtcaagt attgaagcatccacal tca acat acaat atcctctcagATCAT TAAATCCAAGTCTGAGATCGCTGCCCTCAAGGACTTCCTCAACTGGCTTGAGCAACTGAAGACCA

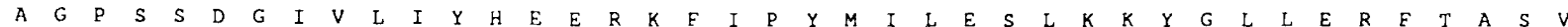
AGGCGGGTCCCAGCTCGGACGGGATTGTGCT TATCTATCATGAAGAGCGCAAGTTCATTCCCTACATGATCCTGGAGTCGTTGAAGAAGTACGGCCTGTTGGAGCGCTTCACCGCGTCGG

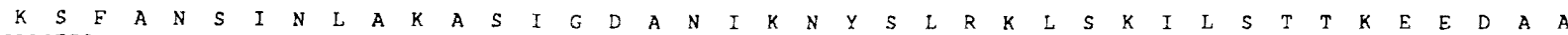
TGAAGTCGTTTGCAAACAGCATCAATCTGGCCAAGGCTTCCATTGGCGATGCCAACATAAAGAACTACAGTCTGCGAAAGCTTTCCAAGATCTTGTCCACGACCAAGGAGGAAGACGCGG

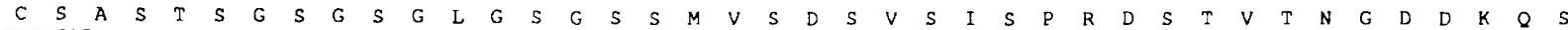
CTTGCTCTGCGTCCACATCTGGATCTGGATCTGGCTTGGGATCTGGATCTAGTATGGTGTCCGATTCGGIATCGATATCCCCCAGGGACAGTACCGTGACCAATGGTGACGATAAGCAAT

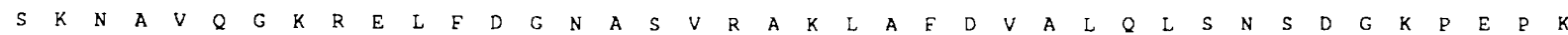
CTAGCAAGAACGCCGTTCAGGGTAAGCGGGAACTGTTTGATGGCAATGCCAGTGTTCGTGCCAAATTGGCCTTTGATGTGGCCCTTCAGCTGAGCAACTCCGACGGCAAGCCGGAACCAA

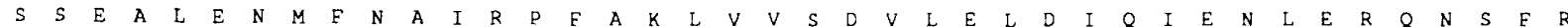
AAAGCTCGGAGGCATTGGAGAATATGTTTAATGCCATACGTCCGTTTGCCAAGTTGGTGGTGTCCGATGTCCTGGAGCTGGATATCCAGATCGAAAATTTGGAGCGTCAAAACTCCTTCC

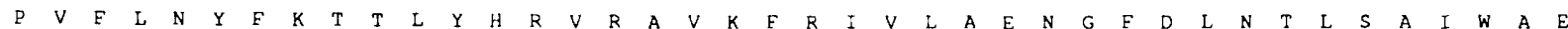
GTCCGGTGTTCCTGAACTACTTCAAGACCACTCTGTACCATCGTGTGCGTGCCGTGAAGTTCCGCATTG:GCTGGCCGAGAATGGGTTCGATTTGAACACGCTAAGTGCCATCTGGGCAG

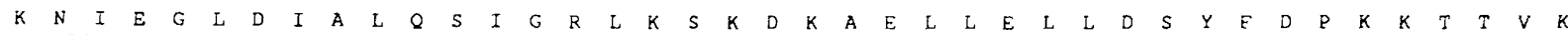
AGAAAAACATCGAGGGCCTGGACATAGCCCTGCAGTCAATTGGCCGGCTAAAGAGCAAGGACAAGGCGGAGCTGCTCGAGCTTCTGGACAGCTATTICGATCCCAAGAAGACCACGGTGA

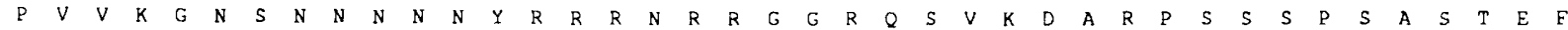
AGCCGGTTGTCAAGGGTAACAGCAACAATAATAACAATT ATCGTCGT CGCAATCGACGCGGCGGCCGCCAATCGG TGAAGGACGCT AGGCCATCCAGCTCCCCATCGGCT AGCACCGAGT

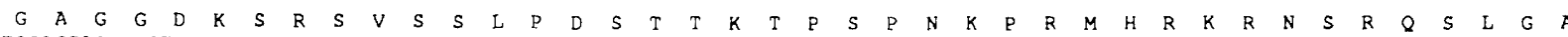
TTGGAGCAGGAGGTGACAAGTCGCGCAGCGTTTCCTCGTTGCCCGACTCTACTACCAAGACTCCCTCGCCAAACAAGCCGCGTATGCACCGTAAGCGCAACTCGCGTCAAAGCTTGGGTG

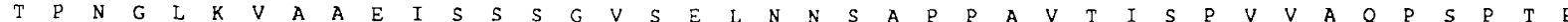
CAACCCCCAATGGACTCAAGGTTGCTGCTGAAATATCCTCCTCAGGCGTGTCTGAGCTCAACAATAGCGCTCCACCTGCCGT AACCATAAGCCCAGTCGTGGCACAACCCTCACCGACAC

$\checkmark$ A I T A S N *

CGGTGGCCATCACGGCCTCCAACTAAAATCCAGTTCTGGTGGATCCGTAAAGTAAATATCTTATATTGAGATACTTCTGCCATTTGCTTTGTAGATAACGTAGTTAACGAGGGGTAAGCC ITCATGTAGATTGTTGATTAATTTTATGAAT TGCGTACACTTGCTTGTATTTTTAATGAATTTTATGCAMCAAATATATTGATAAAAATGTAGCCTTTTTTAGCTAAATGTAAAAGGTTT TATTACATATT TTCAATATAAACTCACAACGCTTAAGCTAATCATTCAAATCACTTTGGGATI TICGGGATTGAGTTTCCTAACCGACATTTTGCCATTTCAGTATATCAAAAAATGGAT GATCAAAACACAAGAAGACAAGGGCAGAGAATGGAGATTTAAACCACATACGAACTTTCTTCCTTTT AGAAGATCTAGTGCAGACAAGCTTTAAATTCCAGTGGAAGCAAATTTCCCGTG AACACAACAAACACATCCGCGCACAACTCACGAGCACGTTGGTGTATCGATAGTGTGAGTAAACCGTGACTGTGACGTAAACAGTGACTGTTGAATAGTGATGACACAAGCTTCAAGCGA CAT TTTTGAAACGAGTGAATTGTTAATCGAGACGTTTGAAAACTATATTGTCCAGCATAGGGAGGATGCMGAGCCCACTGTAAACT CAAGAGACTATATATCCACACTTT AAAGCAGCGT ATGCTAGAAATAATGATGGAGAAGAAGGAACAACAAATATGATGTACAATTAAGAACTCGCTGCGTT TAGGCATAGTT TTCCCGGCGAACCGATGCACATCGCCGCACTCAAATGGGAGA T'TGGGAAAATATGATCCAAAACGAAACGCCTCGATGAAAATTT TCCATTGGACGGGCCTGTCGACGCACACTATCAAAACTCTATGAATAAAACCCAAGATCCAGGCCTAGTCCAATGTA GAAAACTTTCACCTTGAAGCTAAAGAAAGCACGATATAAAAATACACCAATCTAATACAGTTAACCTTACGCACGCACACGCACGCACACAGAAAGCATATTCAATTCGCACACTTAATC TAACCCAACACTTGTGAACATATCCAGTATT TCAAGCTGTATT TCATATATGTTTCATATT'TACAATCAACAAACATATGTAATATCTGCAAAGGGCGGAATAAACGAACGATAAACTA ACGAATCAACAAACATATGTAATATCTGCAAAGGGCGCGAATAAACGAACGATAACCTAACGGTCAGCCTATCGCGCCGAGTCACTGTTTTCACTCTCGCAGGTGCACCGCTAGGTGTGA CCGTATTGCCGCCTGGCCTGGAAAGAGTGGGCCTGTGTGGATTGCTTCCATACCCATACCTGGTGATCAGTGATCACCGATCAGTGCAGCATCGTCCATTTCCCGGCCAGAATGGACGTC GATCCCGCAGAAGAGGCGCCTCTAGA

Figure 2. (See facing page for legend.) 
throughout each nurse cell. In addition, a much lower level of exu protein remains spread evenly throughout the oocyte. This pattern persists until stage 11, when the contents of the nurse cells are transferred to the oocyte. Some residual exu protein remains in the now shrunken nurse cells, while most exu protein becomes dispersed at a low level throughout the oocyte. Notably, there is no specific accumulation of exu protein at the anterior of the oocyte, where bcd mRNA is localized. Finally, in stages 13-14, the oocyte staining disappears, as expected from our failure to detect exu protein in embryos by Western blot analysis (Fig. 3).

Thus, we can divide the pattern of exu protein distribution into three stages: two initial stages in which exu protein is concentrated at sites where $b c d$ mRNA will accumulate, and a late stage in which there is no correlation between exu protein localization and $b c d$ mRNA localization. We define the first stage as being when exu protein and $b c d$ mRNA are present at high levels throughout the oocyte but are largely absent from the nurse cells. We consider this stage separate from the later period of exu protein and $b c d$ mRNA colocalization for two reasons. First, some $b c d$ mRNA does accumulate in the oocyte of exu mutant ovaries (St. Johnston et al. 1989); therefore, exu is not required absolutely for this step. Second, other mRNAs are also localized to the oocyte at the early stages of oogenesis [ $f_{s}(1) K 10$, Haenlin et al. 1987; H.-K. Chung, T. Serano, and R.S. Cohen, pers. comm.; oskar, Kim-Ha et al. 1991; Ephrussi et al. 1991; stau, St. Johnston et al. 1991], suggesting the existence of a more general mechanism for this step. We define the second stage of exu protein distribution as the period when exu protein and $b c d$ mRNA are colocalized at the apical regions of the nurse cells and at the anterior margin of stage 8-10A oocytes. The third stage occurs in the oocyte where exu protein is spread throughout and is apparently degraded uniformly. We now consider the second stage in more detail.

Colocalization of exu protein and $b c d$ mRNA could arise in several different ways, each of which involves a somewhat different role for exu: (1) Exu protein is localized first and then directs localization of $b c d$ mRNA; (2) $b c d$ mRNA is localized first and then directs localization of exu protein; or (3) exu protein and bcd mRNA are localized simultaneously. The second possibility can be ruled out, as $b c d$ mRNA does not become localized in the absence of exu protein. Two types of evidence are in favor of the first explanation. First, in a careful comparison of temporal patterns, exu protein seems to precede $b c d$ mRNA in localization to the apical regions. exu protein first appears concentrated at the apical regions of the nurse cells during stage 8 (Fig. 5), whereas St. Johnston et al. (1989) found that apical localization of bcd mRNA appears rarely in stage 8 and only consistently in stage 9 . We have also obtained similar results, using flies with six copies of the $b c d$ gene (Struhl et al. 1989) to increase the sensitivity of $b c d$ mRNA detection. Nevertheless, a final determination of the temporal sequence of exu protein and $b c d$ mRNA apical localization will require simultaneous detection of both molecules in the same preparations or preferably, the isolation of an RNA-null allele of $b c d$ to determine whether exu protein is still localized. The second line of evidence comes from an examination of the effects of changing the amount of $b c d$ mRNA present in the ovary. If exu protein and $b c d$ mRNA are colocalized simultaneously as a ribonucleoprotein complex, we would expect that by changing the amount of bcd mRNA, the amount of localized exu protein would also be changed. Ovaries from flies with either one or six copies of the bcd gene were compared, monitoring $b c d$ mRNA by in situ hybridization and exu protein by immunohistochemistry. Although the level of $b c d$ mRNA was elevated and correct localization was maintained, there was no striking difference in exu protein staining (data not shown). Again, this analysis would benefit from isolation of a bcd allele that makes no mRNA.

\section{exu protein patterns in mutant ovaries}

We also examined exu protein patterns in ovaries from mutants with defects in the anterior localization pathway, sww and stau. St. Johnston et al. (1989) placed these genes downstream from exu in the anterior localization pathway. Not surprisingly, we find no consistent alteration in exu protein distribution in these mutants /data not shown).

\section{Discussion}

The asymmetric localization of mRNAs within cells is a striking phenomenon of considerable interest in cell and developmental biology. In early stages of development, such mRNAs can provide the localized determinants

Figure 2. DNA sequence of $e x u$. The sequence shown is of a genomic region including most or all of the exu transcription unit. Introns are indicated by lowercase letters, except for the male-specific intron, which is in uppercase letters and underlined. The $5^{\prime}$ end of the transcript has not been determined. Female and male cDNA $3^{\prime}$ ends are each indicated by an $\mathrm{x}$ above the sequence (positions 2794 and 3719, respectively), and the likely polyadenylation signals are overlined. In each case, the presence of two A residues in the genomic DNA makes it impossible to determine the exact site of polyadenylation. The female 3 ' end lies within the male intron; the male $3^{\prime}$ end lies at the end of the first of two copies of a nearly perfect 59-nucleotide direct repeat. The limits of each repeat are marked by carats underneath the DNA sequence $(3655-3723,3724-3782)$. The amino acid sequence of the long ORF is presented above the DNA sequence. Two mini-ORFs upstream from the long ORF are indicated by broken arrows above the DNA sequence, with overlining of the start and stop codons. The sequence of the female cDNA is identical to that of the corresponding sequence, except for a $\mathrm{A} \rightarrow \mathrm{G}$ substitution at position 1976 (no amino acid change). The codon mutated to a stop codon in the mutant $e x u^{S C}$ (positions $1021-1023)$ is underlined. Additional changes in the $e x u^{S C}$ gene are $317, C \rightarrow A ; 531, a \rightarrow t ; 567, a \rightarrow t$; deletion of two a's in the poly(A) run at $717-728 ; 777, \mathrm{~T} \rightarrow \mathrm{C} ; 1616, \mathrm{G} \rightarrow \mathrm{A}(\mathrm{Met} \rightarrow$ Ile) . 


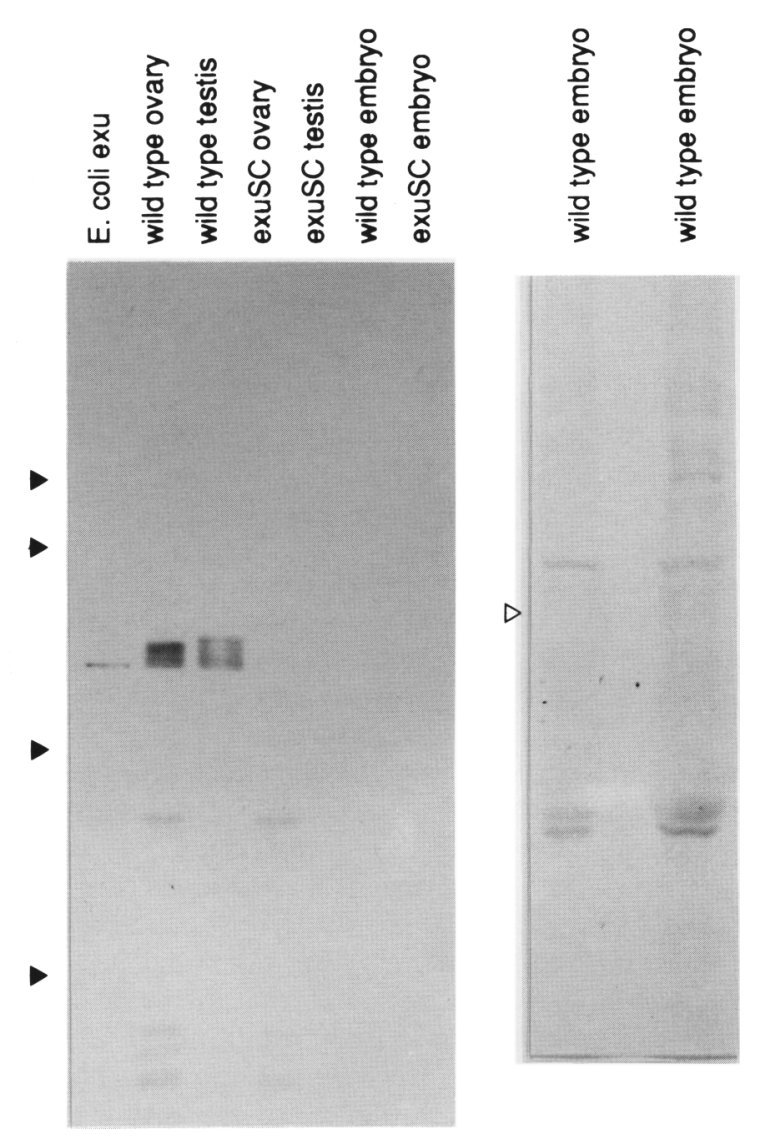

Figure 3. Western blot analysis of exu protein expression. Samples were electrophoresed in SDS-polyacrylamide gels, transferred to nitrocellulose filters, and probed for the presence of exu protein using polyclonal antisera directed against a bacterially produced protein. Lanes are as indicated. (Left) The amount of bacterial protein loaded was adjusted to give a band of similar intensity to the Drosophila samples. Similar amounts of total protein were loaded in all Drosophila lanes, except for the embryo lanes that had two- to threefold less protein. (Right) The blot was overloaded with embryo protein in an attempt to detect even low levels of exu protein/the background bands are due to the abundant yolk proteins, which are faintly visible in the ovary samples at left). The prominent $\sim 60-\mathrm{kD}$ band of exu protein (at left) is present in both wild-type testes and ovaries but is absent in early embryos and in $e x u^{S C}$ ovaries and testes. exu protein in both ovaries and testes migrates as a broad band. In favorable blots, such as the one shown here, exu protein is clearly seen to migrate as a series of six or more narrowly separated bands. The bacterial protein comigrates with the lowest of these bands. The solid arrowheads indicate the positions of size standards: From top to bottom, these are 106, 80, 47.5, and $32.5 \mathrm{kD}$. The open arrowhead \{right\} indicates the position where the exu protein would appear if present.

that specify body patterning (Weeks and Melton 1987; Berleth et al. 1988; Wang and Lehmann 1991). Localization of mRNAs in differentiated cells may be involved in concentrating proteins at the sites where they are most needed (Lawrence and Singer 1986; Garner et al. 1988; Fontaine et al. 1988; Cheng and Bjerknes 1989; Hoock et al. 1991). One prominent example of the localization phenomenon is the positioning of $b c d$ mRNA during oogenesis in Drosophila. This example is well suited for a detailed analysis of the underlying mechanisms, as the cis-acting element responsible for localization has been defined (Macdonald and Struhl 1988) and several genes required for the process have been identified /Schüpbach and Wieschaus 1986; Frohnhöfer and Nüsslein-Volhard 1987; Stephenson et al. 1988; St. Johnston et al. 1989). Furthermore, bcd localization involves several steps, highlighting the complexity of the process and offering insights at several levels. Taken individually, each step may provide generally useful information about how other RNA molecules are localized. Learning how the steps are connected will tell us something about how cells orchestrate elaborate intracellular movements of macromolecules.

$b c d$ mRNA is synthesized in the nurse cells and then moves through cytoplasmic bridges into the oocyte where it is localized at the anterior pole. Because the anterior end of the oocyte abuts the nurse cells, $b c d$ mRNA localization was suggested initially to occur very simply by interaction of the RNA with a receptor in the oocyte (Berleth et al. 1988; Macdonald and Struhl 1988). More recently, St. Johnston et al. (1989) monitored bcd mRNA throughout oogenesis and found that the situation is more complex, involving at least four steps. By extending this analysis to mutant ovaries, they were able to pinpoint the stages where the genes exu, sww, and stau are first required. exu mutants exhibited the earliest alteration in the localization pathway /St. Johnston et al. 1989|, and exu has been suggested to encode a protein that specifically binds to the $b c d$ mRNA localization signal (Berleth et al. 1988). Here, we have characterized the exu gene and its expression. Our results provide direct support for an interaction between exu protein and $b c d$ mRNA but also indicate that the interaction is transient and, possibly, indirect. These results further emphasize the incompleteness of the simplest models of localization and suggest that the role of exu in localization is to direct association of $b c d$ mRNA with other components of the localization machinery.

Evidence supporting the existence of an interaction between exu protein and $b c d$ mRNA comes from our analysis of exu protein distribution during oogenesis. Specifically, we find colocalization of exu protein and $b c d$ mRNA. Because the localization of bcd mRNA is exu dependent, we suggest that the localization of both components to the same position has functional significance. Our studies reveal further that these components are not colocalized persistently. Rather, exu protein and $b c d$ mRNA are colocalized only at a time and place where $b c d$ mRNA first acquires a distribution unlike that of any other characterized mRNA, in the apical regions of the nurse cells. At later stages, when $b c d$ mRNA moves from the nurse cells to the anterior margin of the oocyte, there is no corresponding concentration of exu protein. These results indicate that the role of exu is to initiate one phase of the process by which $b c d$ mRNA is localized but not to play a continuing part in the execution of that process. Nevertheless, this transient inter- 


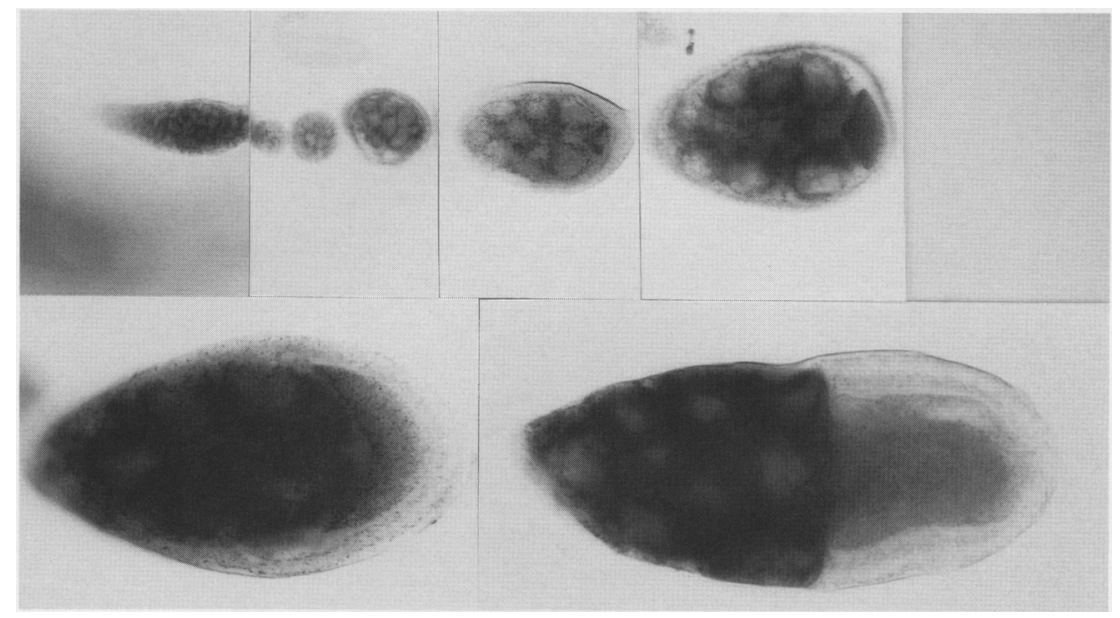

Figure 4. Spatial patterns of exu mRNA expression during oogenesis. A series of progressively more advanced stages of oogenesis are shown: (Top) The germarium: stage 1 , stage 2 , stage 3 or 4 , stage 6 , and stage 7 or 8 ; (bottom) stages 9 and 10. exu mRNA has been detected by in situ hybridization using a whole-mount procedure (Tautz and Pfeifle 1989). Expression of exu is detected initially in regions 2 and 3 of the germarium and continues for the remainder of oogenesis. At stage 3, exu mRNA appears somewhat concentrated in the oocyte relative to the nurse cells. This pattern continues until stage 7 . In subsequent stages, exu mRNA is expressed at much higher levels in the nurse cells relative to the oocyte.

action is essential, because in the absence of exu protein bcd mRNA becomes spread throughout the oocyte. Thus, the movement of bcd mRNA from nurse cells to oocyte is not sufficient for anterior localization.

The interaction between exu protein and bcd mRNA has been suggested to involve direct binding (Berleth et al. 1988). Given our results, if the interaction is direct, then binding of exu to bcd mRNA must necessarily be followed by disassociation. Alternatively, exu may interact indirectly by an intermediate binding protein. At present, these possibilities cannot be distinguished. In either case, there are other important aspects of the interaction that need to be clarified. In particular, what signal or event first directs the initial association of exu protein and $b c d$ mRNA? Similarly, what directs the subsequent release of $b c d$ mRNA from the nurse cells to allow movement into the oocyte? The first step might occur only when a protein that binds to $b c d$ mRNA is synthesized or activated. We cannot distinguish between this and other possibilities, however, nor can we distinguish among the many possibilities for the second step.

If exu protein does not bind directly to $b c d$ mRNA, it will be of considerable interest to identify the protein that does perform this function. Mutations in the $s w w$ and stau genes disrupt bcd mRNA localization but do so only after the initial localization to the apical regions of the nurse cells. Thus, although the sww and stau proteins may at some point bind bcd mRNA directly (St. Johnston et al. 1991), a different protein must bind at the earlier stage. The actual $b c d$ mRNA-binding protein, if not exu itself, may well interact with exu protein, suggesting a biochemical approach for its identification.

In addition to the interaction, direct or indirect, between $b c d$ mRNA and exu protein, it is very likely that exu protein is involved in another interaction. This suggestion comes from the localization of exu protein to apical regions of the nurse cells. Because there is no equivalent concentration of exu mRNA, the preferential accumulation of exu protein presumably occurs as a result of its binding to a fixed subcellular structure in the apical regions. Candidates for such a structure are of two general types: membranes and cytoskeletal elements. The DNA sequence of exu predicts neither an obvious signal sequence nor a membrane-spanning domain. Nevertheless, exu could be membrane bound by its association with a membrane protein. If so, apical localization could stem from polarized movement of vesicles (Matlin and Simons 1984; Rindler et al. 1984; Simons and Fuller 1985 ) or from a specific association with the apical plasma membrane. Alternatively, exu protein localization may involve the cytoskeleton. Indeed, recent studies of $b c d$ mRNA localization in vivo have demonstrated a requirement for cytoskeletal elements. Pokrywka and Stephenson (1991) found that bcd mRNA failed to localize correctly when microtubules were destabilized but that localization occurred normally in the presence of cytochalasin D, a microfilament-destabilizing drug. A role of exu, therefore, may be to associate bcd mRNA with a microtubule-binding protein. Potential interactions of exu protein with membrane and cytoskeletal structures need not be mutually exclusive. Any such interaction must be mediated by a domain of the exu protein, and one candidate domain is the segment with potential to form a coiled-coil structure, a motif implicated in protein-protein interactions (Cohen and Parry 1986). This idea may be tested by molecular genetic dissection of the exu gene and biochemical analysis of exu protein.

\section{Materials and methods}

Fly stocks

$w^{1118}$ flies were used as wild-type controls and as recipients for P-element transformation. Mutant flies are described in Schüpbach and Wieschaus (1986) or in Tearle and Nüsslein-Volhard (1987). Flies carrying multiple copies of the bcd gene have been described (Struhl et al. 1989).

\section{DNA manipulations}

The exu gene was cloned by P-element transposon tagging, with a P-element allele of $e x u$ provided by Trudi Schüpbach. DNA of this mutant was used to prepare a genomic phage library that 
Macdonald et al.

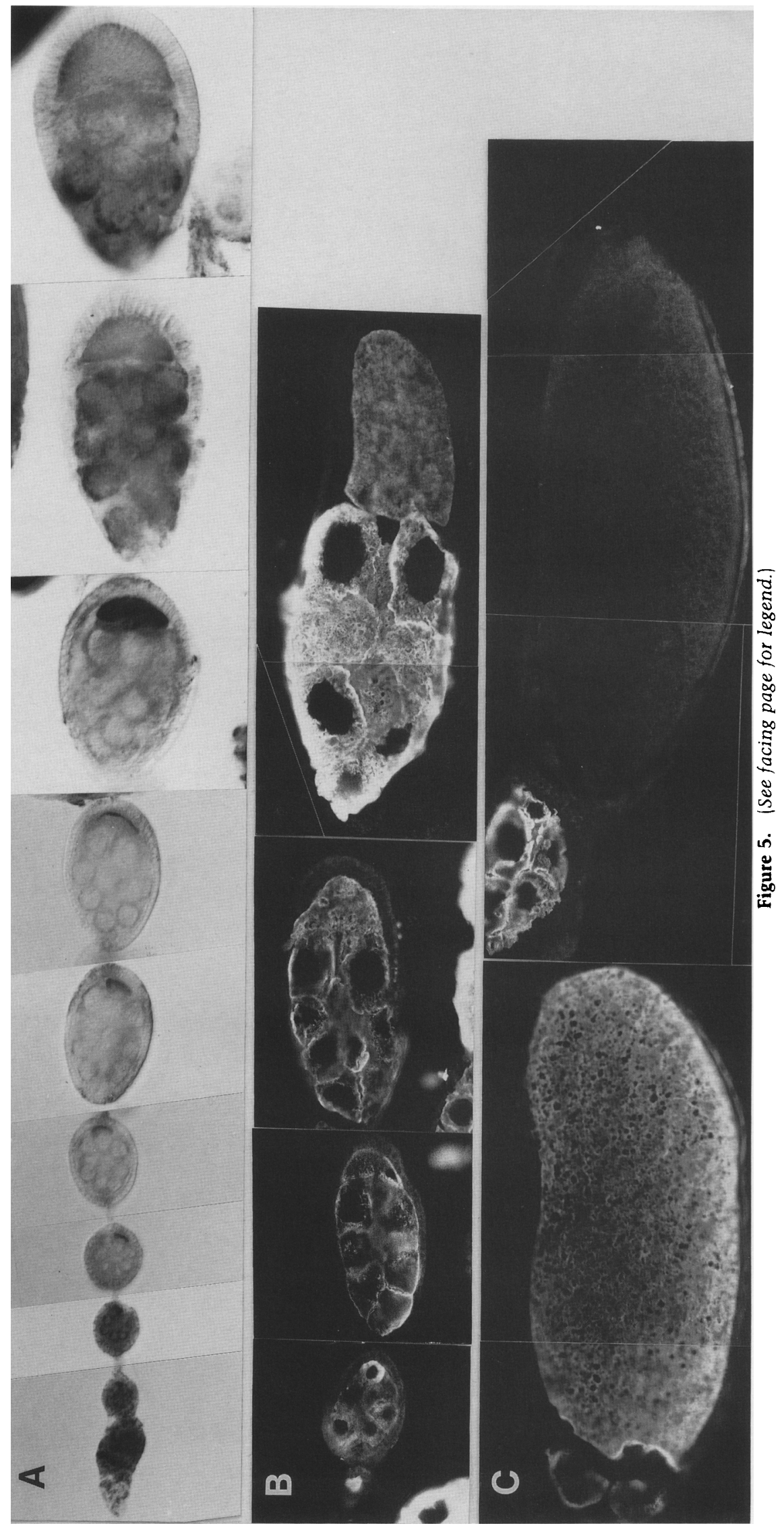




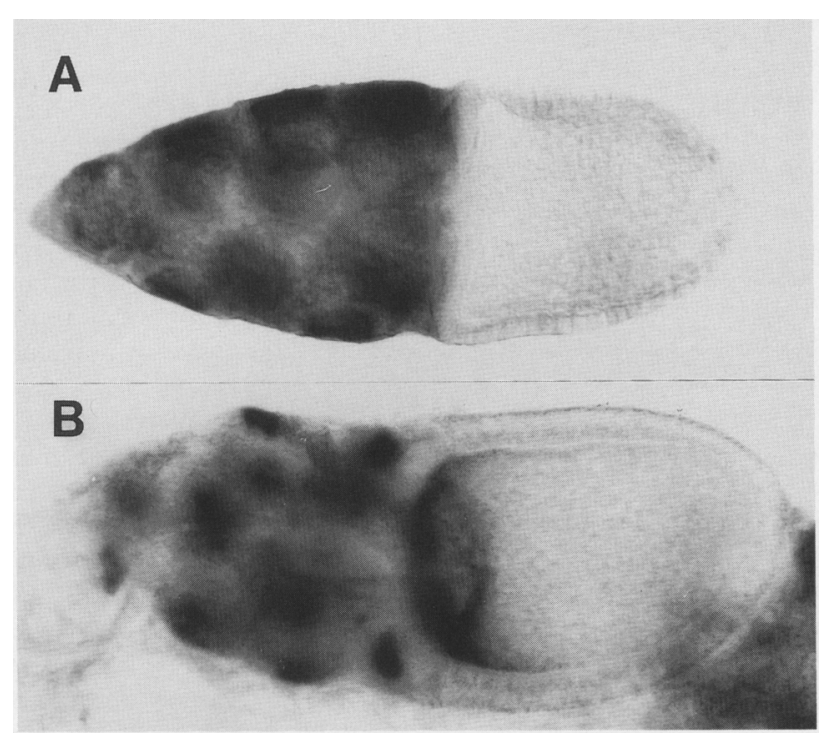

Figure 6. exu protein and $b c d$ mRNA are both localized to the apical regions of the nurse cells. $(A, B)$ Egg chambers in which exu protein and $b c d \mathrm{mRNA}$ have been detected, respectively. St. Johnston et al. (1989) and Stephenson et al. (1988) previously described the localization of $b c d$ mRNA to the apical regions of the nurse cells. In these whole-mount preparations, the optical sections are taken near the center of the nurse cell complexes. The positions of localization between nuclei and outer membranes are seen clearly at the edges of the egg chambers. In nurse cells positioned centrally in these photographs, the apical regions are out of the focal plane, and the localized protein and mRNA can be seen as diffuse patches. Note the presence of $b c d$ mRNA at the anterior margin of the oocyte and the absence of any colocalized exu protein at that site.

was screened with a P-element probe by standard methods. Candidate clones were tested for chromosomal location, and a phage from the exu region was used for further analysis. Northern blots of ovarian RNA were probed with labeled DNA restriction fragments from the phage, and a region transcribed during oogenesis was identified and later shown to be exu. cDNA clones of exu were obtained from ovarian and male cDNA libraries, provided by Laura Kalfayan and Steve Elledge, respectively.

DNA sequencing of genomic and cDNA clones of exu was performed by standard methods using Sequenase version 2.0 (U.S. Biochemical) according to the manufacturer's directions. Sequencing reactions were performed using both dGTP and dITP to resolve ambiguities.

To characterize the $e x u^{S C}$ allele, DNA was prepared from homozygous mutant males and the exu gene was amplified by polymerase chain reaction (PCR) (Saiki et al. 1985). Amplification was done in two parts. Oligonucleotide primers to amplify the region from nucleotide 255 in Figure 2 and extending to nucleotide 1588 were $5^{\prime}$-ATGTGGACGAGTTGCAGCTGTCTA and 5'-GCAAGCCGCGTCTTCCTCCTTGG. Primers used to amplify the region from nucleotide 1403-2968 were 5'-CCCTACATGATCCTGGAGTCGTTG and 5'-AAGGAAGAAAGTTCGTATGTGGTT. PCR reactions followed the suggestions of Innis and Gelfand (1990) and were performed in 100$\mu$ l volumes (overlaid with $75 \mu$ l of mineral oil) containing 1.5 $\mathrm{mM} \mathrm{MgCl}_{2}, 50 \mathrm{mM} \mathrm{KCl}, 10 \mathrm{mM}$ Tris- $\mathrm{HCl}$ (pH 8.0), $50 \mu \mathrm{M}$ each dATP, dCTP, dGTP, and dTTP, 20 pmoles of each primer, 100 $\mu \mathrm{g} / \mathrm{ml}$ of gelatin, $\sim 1 \mu \mathrm{g}$ of Drosophila genomic DNA, and 2 units of Taq DNA polymerase (Amersham). All components except for the polymerase were assembled in $0.5-\mathrm{ml}$ microcentrifuge tubes and boiled for $5 \mathrm{~min}$. After some cooling at room temperature, the polymerase was added and the amplification was performed in a thermal cycler (MJ Research, Inc.). Twentyfive cycles of $20 \mathrm{sec}$ at $94^{\circ} \mathrm{C}, 30 \mathrm{sec}$ at $55^{\circ} \mathrm{C}$, and $90 \mathrm{sec}$ at $72^{\circ} \mathrm{C}$ were followed by a 5 -min incubation at $72^{\circ} \mathrm{C}$. PCR products were purified by phenol-chloroform extraction and ethanol precipitation and were isolated after agarose gel electrophoresis. The fragments were cloned into pGEMI (Promega Biotech) and subjected to double-stranded dideoxy sequencing with Sequenase and a series of internal oligonucleotide primers. DNA sequence corresponding to positions $321-2589$ in Figure 2 was determined. Despite the use of conditions designed to minimize replication errors during PCR, there were several changes. Consequently, to distinguish bona fide mutations from replication

Figure 5. Spatial patterns of exu protein distribution in ovaries. Distribution of exu protein was monitored in whole-mount preparations and in frozen sections. Whole-mount preparations were used for early stages. At late stages, the presence of the vitelline membrane renders the oocyte inaccessible to antibodies, and frozen sections were used to avoid this problem. Ovaries from $e x u^{s C}$, $e x u^{S C}$ females were used as negative controls for these experiments. The $e x u^{S C}$ mutation truncates the protein early in the ORF (Fig. 2) and makes no detectable protein as determined by Western blot analysis (Fig. 3). (A) Distribution of the exu protein in early and middle stages of oogenesis was monitored by immunohistochemical analysis of whole-mount preparations. The stages shown extend from the germarium to stage 9 . exu protein first appears in regions 2 and 3 of the germarium; however, no distinguishable localization can be observed at this stage. From stages 1 through 6 , exu protein is localized to the presumptive oocyte. The signal remains intense through stages 7 and 8 despite expansion of the oocyte. A distinct patchy distribution of the exu protein begins to appear in the nurse cells at these later stages. At stages 9, 10A, and 10B, the patchy staining becomes more prominent (Fig. 6). During stages 8-10, in the oocyte there is a slight enrichment of exu protein at the cortex. $(B, C)$ Distribution of exu protein in middle and late stages of oogenesis. Frozen sections were prepared as described in Materials and methods, and exu protein was detected by immunofluorescence using rat primary antisera and fluorescein-coupled secondary antibody. $(B)$ A series of progressively more advanced egg chambers. In the first egg chamber (stage 5 or 6 ), exu protein is present throughout the cytoplasm of all 16 cells but is concentrated in the oocyte. By stages $8-9$ (second and third egg chambers), exu protein has accumulated to higher levels in the nurse cells, and beginning at this time there is a noticeable concentration of the protein in the apical regions. At stage 10B (last egg chamber), exu protein is present at high levels throughout the nurse cells, although higher concentrations are still found at the apical regions. In the oocyte, exu protein is present uniformly, with no apparent concentration at the anterior margin. (C) Stage 12 and 14 egg chambers. During stage 11 , the contents of the nurse cells are transferred into the oocyte. Most of the exu protein is included in this movement, yielding the uniform oocyte distribution seen at stage 12 . From stage 11 to 13 the amount of exu protein decreases gradually such that none can be detected by stage 14. Uneven illumination in the microscope is responsible for the apparent ventral concentration of exu protein seen in the stage 12 oocyte and less noticeably in other egg chambers. 
errors, we reamplified the gene and resequenced all regions in which changes were detected.

Several constructs were made to express different parts of the exu gene in Escherichia coli. All employed the pET expression vectors of Rosenberg et al. (1987). p569 directs expression of the full-length exu protein containing no bacterial sequences and was constructed by PCR-mediated introduction of an NdeI site at the ATG codon of the cDNA and subsequent cloning of the modified cDNA into pET3a. p574 is a derivative of p569 in which the internal HindIII fragment from the exu gene has been removed and replaced with an NheI linker that introduces stop codons in all reading frames. p574, therefore, directs expression of the amino-terminal 191 amino acids of exu. In p559, a cDNA fragment including the region corresponding to amino acids 194-531 was cloned into pET3c. In p575, a cDNA fragment including the region corresponding to amino acids 375-502 was cloned into pET3b.

\section{P-element transformation and mutant rescue}

To test for rescue of the exu mutant phenotype by P-element transformation, a 7.4-kb EcoRI exu genomic DNA fragment /the region shown in Fig. 2) was inserted into the CaSpeR vector (Pirotta 1988) to make pS200. DNA of pS200 was introduced into the germ line of $w^{1118}$ flies by P-element-mediated transformation (Rubin and Spradling 1982). Transformants were identified by eye color, and balanced stocks were established for independent lines. Ten different lines with insertions on the third chromosome were placed in the $e x u^{S C}$ background by the appropriate crosses. Virgin females of the genotype exu ${ }^{S C /}$ $\mathrm{exu}^{S C}$; $P[S 200-\mathrm{x}$ ]/TM2 (where $-\mathrm{x}$ refers to the individual lines) were crossed to wild-type males to test for rescue of maternaleffect lethality. All of these crosses yielded viable and fertile progeny, demonstrating that a single copy of the cloned exu gene can rescue the maternal-effect lethality of $e x u^{S C}$ mutants. To test for the ability to rescue the male sterility defect, males of the genotype $\left.e x u^{S C} / e x u^{S C} ; P / S 200-x\right] / T M 2$ were crossed to $w^{1118}$ virgin females. For each of five lines examined, the males were only weakly fertile, although the results were not quantitated. Three of these transformant lines were also examined as homozygotes, with no noticeable improvement in male fertility. Thus, this construct does not appear to include all sequences necessary for normal expression of exu in males.

We also used the transformant stocks to test the effects of altered exu copy number on anterior patterning. Previous work with $b c d$ has suggested that the localization machinery is in excess (Driever et al. 1989; Struhl et al. 1989). Given this, it is not surprising that increasing the exu gene copy number to six had no effect, as measured by two independent assays. There was no change in the position of the anterior zone of hunchback expression, and there was no noticeable change in the pattern of bcd mRNA localization at any stage of oogenesis /data not shown).

\section{Antibodies, immunoblotting, immunohistochemistry,} and immunofluorescence

exu proteins expressed in E. coli (see above) were purified partially and used for antisera production in rats.

For Western blot analysis, crude extracts of Drosophila samples were electrophoresed on SDS-polyacrylamide gels. The gels were soaked in transfer buffer $150 \mathrm{~mm}$ Tris base, $40 \mathrm{~mm}$ glycine, $0.04 \%$ SDS, $20 \%$ methanol) for $15-30 \mathrm{~min}$, and the proteins were transferred electrophoretically to nitrocellulose in a semidry transfer apparatus (Bio-Rad) according to the manufacturer's instructions. Blots were blocked in binding buffer
$[150 \mathrm{~mm} \mathrm{NaCl}, 10 \mathrm{~mm}$ Tris- $\mathrm{HCl} \mid \mathrm{pH} 7.5$ ) $3 \%$ BSA, $0.05 \%$ thimerosol] for $30 \mathrm{~min}$. After several short washes in washing buffer $[150 \mathrm{~mm} \mathrm{NaCl}, 10 \mathrm{~mm}$ Tris- $\mathrm{HCl}(\mathrm{pH} 7.5), 0.05 \%$ Tween $20]$, the blots were incubated for $2-4 \mathrm{hr}$ at room temperature with the primary antibody diluted 1:1000 in binding buffer. The blots were then rinsed several times in washing buffer and incubated with alkaline phosphatase (AP)-coupled secondary antibodies of the appropriate specificity. After several further washes, the AP reaction was developed in AP buffer containing 5-bromo-4-chloro-3-indolylphosphate $p$-toluidine and nitro blue tetrazolium.

Immunohistochemical analysis of whole-mount ovary preparations was performed as follows. Ovaries were dissected from young, well-fed adult females, and the ovarioles were teased apart in PBS. In some cases, the ovaries were incubated in 0.375 $\mathrm{M} \mathrm{KCl}$ in $\mathrm{PBS}$ at $37^{\circ} \mathrm{C}$ for $30 \mathrm{~min}$. This step significantly enhanced detection of exu protein in early stages of oogenesis but did not appear to affect its distribution. The ovaries were washed with PBS twice for 2 min before fixing in $4 \%$ formaldehyde in $0.1 \mathrm{M}$ PIPES, $2 \mathrm{mM} \mathrm{MgSO}_{4}$, for $20 \mathrm{~min}$ at room temperature. The fixative was removed by washing extensively with PBS containing $0.1 \%$ Tween 20 (PBT). After the final wash, anti-exu antisera were added at a dilution of $1: 150$ in $50 \mathrm{~mm}$ Tris- $\mathrm{HCl}(\mathrm{pH} 7.5), 150 \mathrm{~mm} \mathrm{NaCl}, 0.1 \%$ BSA, $0.1 \%$ Triton X-100, and $0.05 \%$ thimerosol (TNBTT) and incubated overnight at $4{ }^{\circ} \mathrm{C}$ Ovaries were washed twice with TNBTT and incubated with $2 \%$ goat serum in TNBTT for $30 \mathrm{~min}$. The ovaries were washed once again in TNBTT at least twice for $1 \mathrm{hr}$. Secondary antibody [horseradish peroxidase ( $\mathrm{HRP}$ |-conjugated goat anti-rat $\mathrm{IgG}$ ) was added at a dilution of $1: 2000$ and incubated for $2 \mathrm{hr}$ at room temperature. After washing the ovaries at least three times with PBT for $15 \mathrm{~min}$, the HRP reaction was developed with diaminobenzidine and hydrogen peroxide. The reaction was stopped by washing the ovaries several times with PBS. Stained ovaries were mounted in GMM.

Immunofluorescent detection of exu protein was performed on frozen sections. Ovaries were collected and prefixed as for immunohistochemistry, without the treatment in $0.375 \mathrm{M} \mathrm{KCl}$. After washing in PBS, the prefixed ovaries were embedded in OCT compound (Tissue-Tek) and sectioned with a cryostat. Sections were mounted on polylysine-coated slides, allowed to air-dry for at least $20 \mathrm{~min}$, and postfixed for $20 \mathrm{~min}$ in $2 \%$ formaldehyde in PBS. After washing once in $3 \times$ PBS and twice in PBS, the slides were incubated with exu antiserum diluted $1: 150$ in TNBTT for 4-12 hr. The slides were then washed twice in TNBTT, incubated for $30 \mathrm{~min}$ in TNBTT containing $2 \%$ goat serum, and washed several times in TNBTT. Fluorescein-coupled goat anti-rat secondary antibody (Jackson Immunoresearch/ was added at a dilution of $1: 1000$ in TNBTT and incubated for 1-2 hr. After three washes in PBT, the sections were mounted in a freshly prepared solution of $0.1 \mathrm{M}$ sodium bicarbonate, $50 \%$ glycerol, containing a few crystals of $p$-phenylenediamine per $10 \mathrm{ml}$. Sections were viewed and photographed with a Zeiss Axiophot microscope.

\section{Acknowledgments}

We thank Atsuko Nakanishi for performing the fly injections, Trudi Schüpbach and Christiane Nüsslein-Volhard for fly stocks, Vince Pirotta for CaSpeR vector DNA, Laura Kalfayan and Steve Elledge for their cDNA libraries, Mitzi Kuroda and Young Kim for the developmental Northern blot, and Craig Heller for the use of his cryostat. Jeffrey Smith and Elena Casey constructed pS200 and p569, respectively. Ellen Sutin kindly provided advice on sectioning. We also thank Lex Bunten for 
assistance in preparing the manuscript and Bruce Baker, Brian Oliver, Gary Struhl, Robin Wharton, and Joan Wilson for discussions and/or critical reviews of the manuscript. This work was supported by a grant from the National Institutes of Health (GM42612). Initial work on cloning the exu gene was done in Gary Struhl's laboratory at Columbia University and was supported there by the Howard Hughes Medical Institute. P.M.M. is a Pew Scholar in the Biomedical Sciences and is the recipient of a Packard fellowship.

The publication costs of this article were defrayed in part by payment of page charges. This article must therefore be hereby marked "advertisement" in accordance with 18 USC section 1734 solely to indicate this fact.

\section{References}

Berleth, T., M. Burri, G. Thoma, D. Bopp, S. Richstein, G. Frigerio, M. Noll, and C. Nüsslein-Volhard. 1988. The role of localization of bicoid RNA in organizing the anterior pattern of the Drosophila embryo. EMBO I. 7: 1749-1756.

Cheng, H. and M. Bjerknes. 1989. Asymmetric distribution of actin mRNA and cytoskeletal pattern generation in polarized epithelial cells. J. Mol. Biol. 210: 541-549.

Cohen, C. and D.A.D. Parry. 1986. Alpha-helical coiled cells-A widespread motif in proteins. Trends Biochem. Sci. 11: 245248.

Driever, W. and C. Nüsslein-Volhard. 1988a. A gradient of bicoid protein in Drosophila embryos. Cell 54: 83-93.

- $1988 \mathrm{~b}$. The bicoid protein determines position in the Drosophila embryo in a concentration-dependent manner. Cell 54: 95-104.

1989. The bicoid protein is a positive regulator of hunchback transcription in the early Drosophila embryo. Nature 337: 138-143.

Driever, W., G. Thoma, and C. Nüsslein-Volhard. 1989. Determination of spatial domains of zygotic gene expression in the Drosophila embryo by the affinity of binding sites for the bicoid morphogen. Nature 340: 363-367.

Ephrussi, A., L.K. Dickinson, and R. Lehmann. 1991. oskar organizes the germ plasm and directs localization of the posterior determinant nanos. Cell 66: 37-50.

Fontaine, B., D. Sassoon, M. Buckingham, and J.-P. Changeux 1988. Detection of the nicotinic acetylcholine receptor al pha-subunit mRNA by in situ hybridization at neuromuscular junctions of 15 -day-old chick striated muscles. EMBO $\%$ 7: 603-609.

Frigerio, D., M. Burri, D. Bopp, S. Baumgartner, and M. Noll. 1986. Structure of the segmentation gene paired and the Drosophila PRD gene set as a part of a gene network. Cell 47: 735-746.

Frohnhöfer, H.G. and C. Nüsslein-Volhard. 1986. The organization of anterior pattern in the Drosophila embryo by the maternal gene bicoid. Nature 324: 120-125.

1987. Maternal genes required for the anterior localization of bicoid activity in the embryo of Drosophila. Genes \& Dev. 1: 880-890.

Garner, C.C., R.P. Tucker, and A. Matus. 1988. Selective localization of messenger RNA for cytoskeletal protein MAP2 in dendrites. Nature 336: 674-677.

Haenlin, M., C. Roos, A. Cassab, and E. Mohier. 1987. Oocytespecific transcription of fs(1)K20: A Drosophila gene affecting dorsal-ventral developmental polarity. $Е M B O$ I. 6: 801807.

Hay, B., L. Ackerman, S. Barbel, L. Jan, and Y.N. Jan. 1988. Identification of a component of Drosophila polar granules.
Development 103: 625-640.

Hay, B., L.Y. Jan, and Y.N. Jan. 1990. Localization of vasa, a component of Drosophila polar granules, in maternal-effect mutants that alter embryonic anteroposterior polarity. $D e$ velopment 109: 425-433.

Hazelrigg, T., W.S. Watkins, D. Marcey, C. Tu, M. Karow, and $\mathrm{X}$. Lin. 1990. The exuperantia gene is required for Drosophila spermatogenesis as well as anteroposterior polarity of the developing oocyte, and encodes overlapping sex-specific transcripts. Genetics 126: 607-617.

Hoock, T.C., P.M. Newcomb, and I.M. Herman. 1991. $\beta$ Actin and its mRNA are localized at the plasma membrane and the regions of moving cytoplasm during the cellular response to injury. I. Cell Biol. 112: 653-664.

Innis, M.A. and D.H. Gelfand. 1990. Optimization of PCRs. In PCR protocols. A guide to methods and applications (ed. M.A. Innis, D.H. Gelfand, I.J. Sninsky, and T.J. White). Academic Press, San Diego, CA.

Kim-Ha, J., J.L. Smith, and P.M. Macdonald. 1991. oskar mRNA is localized to the posterior pole of the Drosophila ooctye. Cell 66: 23-35

King, R.C. 1970. Ovarian development in Drosophila melanogaster. Academic Press, New York.

Lasko, P.F. and M. Ashburner. 1990. Posterior localization of vasa protein correlates with, but is not sufficient for, pole cell development. Genes \& Dev. 4: 905-921.

Lawrence, J.B. and R.H. Singer. 1986. Intracellular localization of messenger RNAs for cytoskeletal proteins. Cell 45: 407415

Macdonald, P.M. and G. Struhl. 1988. Cis-acting sequences responsible for anterior localization of bicoid mRNA in Drosophila embryos. Nature 336: 595-598.

Mahowald, A.P. and M.P. Kambysellis. 1978. Oogenesis. In $\mathrm{Ge}$ netics and biology of Drosophila (ed. M. Ashburner and T.R.F. Wright), vol. 2, pp. 141-224. Academic Press, New York.

Mancebo, R., P.C.H. Lo, and S.M. Mount. 1990. Structure and expression of the Drosophila melanogaster gene for the Ul small nuclear ribonucleoprotein particle $70 \mathrm{~K}$ protein. $\mathrm{Mol}$. Cell. Biol. 10: 2492-2505.

Matlin, K.S. and K. Simons. 1984. Sorting of an apical membrane glycoprotein occurs before it reaches the cell surface in cultured epithelial cells. I. Cell Biol. 99: 2131-2139.

Nüsslein-Volhard, C., H.G. Frohnhöfer, and R. Lehmann. 1987. Determination of anteroposterior polarity in Drosophila. Science 238: 1675-1681.

Pirotta, V. 1988. Vectors for P-mediated transformation in Drosophila. In Vectors: A survey of molecular cloning vectors and their uses (ed. R.L. Rodriguez and D.T. Denhardt), pp. 437-456. Butterworths, Boston, MA.

Pokrywka, N.J. and E.C. Stephenson. 1991. Microtubules mediate the localization of bicoid RNA during Drosophila oogenesis. Development 113: 55-66.

Rindler, M.J., I.E. Ivanov, H. Plesken, E. Rodriguez-Boulan, and D.D. Sabatini. 1984. Viral glycoproteins destined for apical or basolateral plasma membrane domains transverse the same Golgi apparatus during their intracellular transport in Madin-Darby canine kidney cells. I. Cell Biol. 98: 1304 1319.

Rosenberg, A.H., B.N. Lade, D. Chui, S. Lin, J.J. Dunn, and F.W. Studier. 1987. Vectors for selective expression of cloned DNAs by T7 RNA polymerase. Gene 56: 125-135.

Rubin, G.M. and A.C. Spradling. 1982. Genetic transformation of Drosophila with transposable element vectors. Science 218: 348-353.

Saiki, R.K., S. Scharf, F. Faloona, K.B. Mullis, G.T. Horn, H.A. 
Macdonald et al.

Erlich, and N. Arnheim. 1985. Enzymatic amplification of $\beta$-globin genomic sequences and restriction site analysis for diagnosis of sickle cell anemia. Science 230: 1350-1354.

St. Johnston, D., W. Driever, T. Berleth, S. Richstein, and C. Nüsslein-Volhard. 1989. Multiple steps in the localization of bicoid RNA to the anterior pole of the Drosophila oocyte. Development (suppl.) 107: 13-19.

St. Johnston, D., D. Beuchle, and C. Nüsslein-Volhard. 1991. staufen, a gene required to localize maternal RNAs in the Drosophila egg. Cell 66: 51-63.

Schüpbach, T. and E. Wieschaus. 1986. Maternal-effect mutations altering the anterior-posterior pattern of the Drosophila embryo. Wilhelm Roux's Arch. Dev. Biol. 195: 302317.

Simons, K. and S.D. Fuller. 1985. Cell surface polarity in epithelia. Annu. Rev. Cell Biol. 1: 243-288.

Smoller, D., C. Friedel, A. Schmid, D. Bettler, L. Lam, and B. Yedvobnick. 1990. The Drosophila neurogenic locus mastermind encodes a nuclear protein unusually rich in amino acid homopolymers. Genes \& Dev. 4: 1688-1700.

Stephenson, E.C., Y. Chao, and J.D. Fackenthal. 1988. Molecular analysis of the swallow gene of Drosophila melanogaster. Genes Dev. 2: 1655-1665.

Struhl, G., K. Struhl, and P.M. Macdonald. 1989. The gradient morphogen bicoid is a concentration-dependent transcriptional activator. Cell 57: 1259-1273.

Tautz, D. and C. Pfeifle. 1989. A nonradioactive in situ hybrid ization method for the localization of specific RNAs in Drosophila embryos reveals a translational control of the segementation gene hunchback. Chromosoma 98: 81-85.

Tearle, R. and C. Nüsslein-Volhard. 1987. Tübingen mutants and stocklist. Dros. Inf. Serv. 66: 209-269.

Wang, C. and R. Lehmann. 1991. Nanos is the localized posterior determinant in Drosophila. Cell 66: 637-647.

Weeks, D.L. and D.A. Melton. 1987. A maternal mRNA localized to the vegetal hemisphere in Xenopus eggs codes for a growth factor related to TGF- $\beta$. Cell 51: $861-867$.

Wharton, K.A., B. Yedvobnick, V.G. Finnerty, and S. ArtavanisTsakonas. 1985. Opa: A novel family of transcribed repeats shared by the Notch locus and other developmentally regulated loci in D. melanogaster. Cell 40: 55-62.

Wharton, R.P. and G. Struhl. 1989. Structure of the Drosophila BicaudalD protein and its role in localizing the posterior determinant nanos. Cell 59: 881-892. 


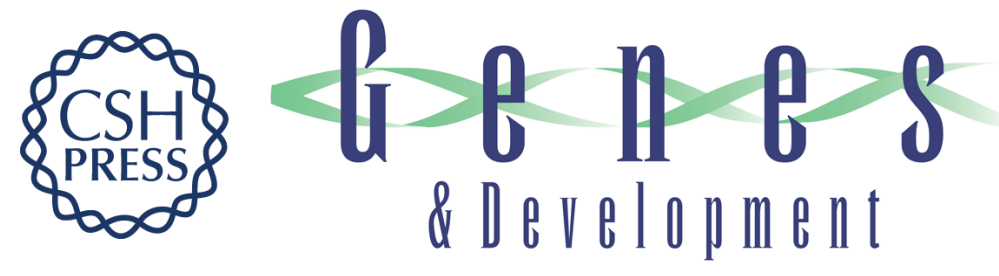

\section{Protein encoded by the exuperantia gene is concentrated at sites of bicoid mRNA accumulation in Drosophila nurse cells but not in oocytes or embryos.}

P M Macdonald, S K Luk and M Kilpatrick

Genes Dev. 1991, 5:

Access the most recent version at doi:10.1101/gad.5.12b.2455

References This article cites 43 articles, 16 of which can be accessed free at:

http://genesdev.cshlp.org/content/5/12b/2455.full.html\#ref-list-1

License

Email Alerting Service

Receive free email alerts when new articles cite this article - sign up in the box at the top right corner of the article or click here.

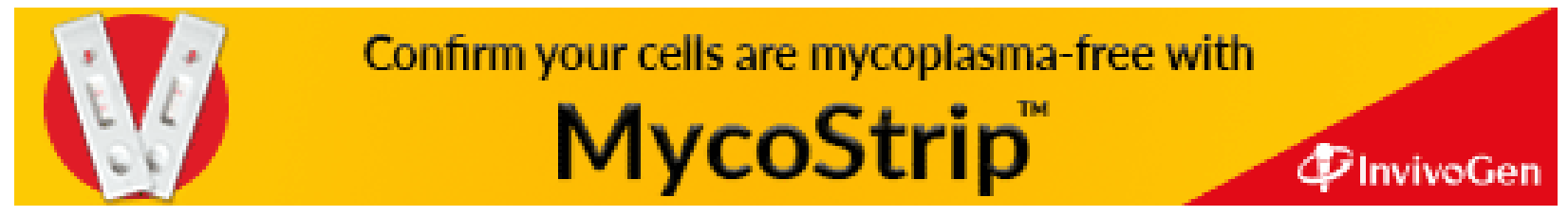

